\title{
Agent Orange
}

National Cancer Institute

\section{Source}

National Cancer Institute. Agent Orange. NCI Thesaurus. Code C33901.

Code name for a synthetic defoliant developed for military use. Agent Orange is a mixture of two chemicals, 2,4, dichlorophenoxyacetic acid (2,4-D) and 2,4,5 trichlorophenoxyacetic acid $(2,4,5-\mathrm{T})$. The toxicity of Agent Orange is due to by-products from metabolic processes upon intake. The toxic by products are dioxin derivatives, which have been linked to the wasting syndrome, gastric ulcer, cancer, immunotoxicity, hepatotoxicity, vascular lesions, teratogenicity, and impaired reproductive performance. $(\mathrm{NCl04})$ 